\title{
STRUCTURE OF SURFACE-MELTED ZONE OF CAST HIGH-NICKEL ALLOY KhN56MBYuDSh AFTER LASER SURFACE TREATMENT
}

\author{
A.A. POLISHKO, V.Ya. SAENKO, A.Yu. TUNIK and S.N. STEPANYUK \\ E.O. Paton Electric Welding Institute, NASU \\ 11 Bozhenko Str., 03680, Kiev, Ukraine. E-mail: office@paton.kiev.ua
}

\begin{abstract}
The laser surface treatment influences greatly the structure and service properties of products. The effect of this treatment on high-nickel alloys used in critical structures represents the interest. The effect of laser surface treatment on structure and properties of cast high-nickel alloy KhN56MBYuDSh was evaluated. Presented are the results of investigations of dispersity of dendrtitic structure obtained by the method of electroslag remelting (ESR) of hollow ingot of this alloy and surface-melted zone after its laser surface treatment in the nitrogen and helium atmosphere. It is shown that in the surface-melted zone the distance between the branches of dendrites is by 2 orders smaller than in cast metal in the state after ESR without the laser treatment. The results of durometric investigations are given. It was found that after the laser treatment the characteristics of microhardness are averaged within the whole volume of the melted layer. In addition, the increase in level of microhardness of the melted layer in nitrogen is observed. Generally, the positive effect of this treatment on structure and microhardness of the surface-melted zone was found. 6 Ref., 4 Tables, 8 Figures.
\end{abstract}

Key words: laser surface treatment, high-nickel alloy, surface-melted zone, metallographic examinations, dendritic structure, distance between the primary branches of dendrites, distance between the secondary branches of dendrites, durometric investigations, microhardness

The laser treatment of surface is one of the challenging methods of solution of problems of the nowadays materials science in the formation of a surface working layer with preset structure and properties. During laser treatment of steels and alloys using surface melting, the surface layers can be heated for a very short time up to high temperatures and melted. In the overheated metal the impurities can be redistributed if they were previously in the form of inclusions. As the time of heating and thickness of molten layer are very small, the cooling in crystallization of the molten layer occurs at a high rate. As a result, the highrate crystallization of the surface layer, melted by a laser beam, opens up the new opportunities for producing the radically new structural state in the surface-melted zone of cast alloys as compared with traditional welding and metallurgical processes.

Many researchers showed [1, 2] that the significant strengthening effect of the surface layer can be obtained in laser treatment with surface melting, which allows regulating easily the thickness of the strengthened layer, and also the degree of its strengthening in the presence of phase trans-

(c) A.A. POLISHKO, V.Ya. SAENKO, A.Yu. TUNIK and S.N. STEPANYUK, 2014 formations. The possibility of laser surface alloying from a gas phase, in particular with nitrogen, is also important [3]. The strengthening in this case is connected with the formation of oversaturated solid solutions and new phases. The undoubted advantage of application of laser method is the possibility of surface treatment of thinwalled parts with regulated thickness and properties of strengthened layer at their minimum shrinkages, as well as developed, including inner, surfaces.

The aim of the present work is the investigation of effect of laser surface treatment on structure and hardness of surface-melted zone of ingot of high-nickel alloy of KhN56MBYuDSh grade (TU-14-1-4025-85), produced by ESR method.

As an object of investigation the specimens of cast metal cut out from a hollow ingot, produced by ESR method, of $350 / 230 \mathrm{~mm}$ diameter and $1600 \mathrm{~mm}$ height of alloy KhN56MBYuDSh, were used.

Technology of producing thick-walled hollow billets of alloy KhN56MBYuDSh using the ESR method was developed for the first time in 19881990 at the E.O. Paton Electric Welding Institute of the NAS of Ukraine under the supervision of Prof. B.I. Medovar in collaboration with N.A. Dollezhal Research and Development Institute of Power Engineering of the RAS as applied to highly-loaded elements of structures of nuclear power units with gas heat carriers [4-6]. 


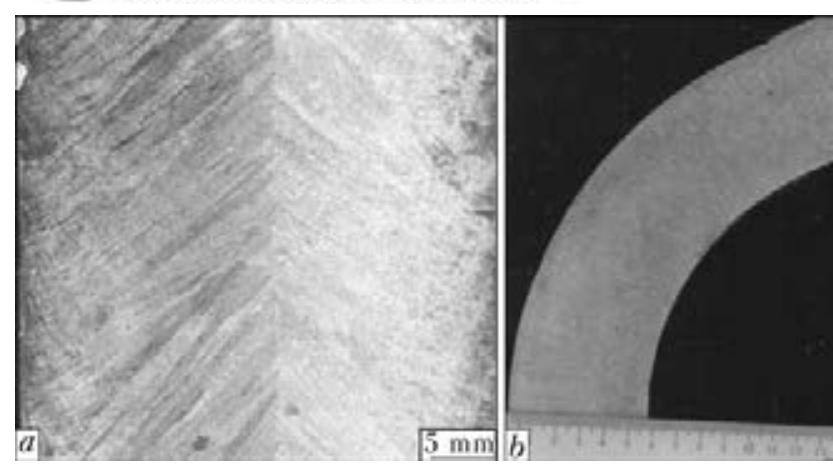

Figure 1. Macrostructure of fragments of longitudinal $(a)$ and transverse $(b)$ templates of $350 / 230 \mathrm{~mm}$ diameter and $1600 \mathrm{~mm}$ height hollow ingot of alloy KhN56MBYuDSh produced by ESR

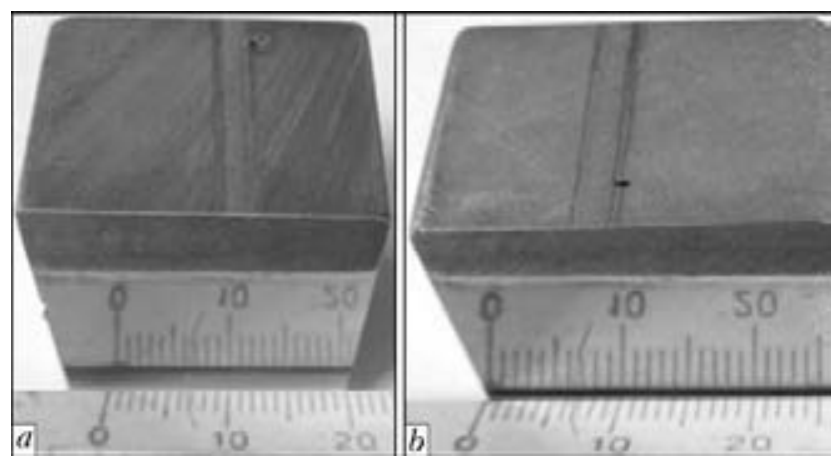

Figure 2. Appearance of specimens after laser surface melting in nitrogen $(a)$ and helium $(b)$

Chemical composition of alloy KhN56MBYuDSh (TU-14-1-4025-85) is the following, wt.\%: $0.041 \mathrm{C} ; 1.65 \mathrm{Al} ; 0.4 \mathrm{Si} ; 0.48 \mathrm{Ti}$; $0.4 \mathrm{~V} ; 19 \mathrm{Cr} ; 10 \mathrm{Fe} ; 5.3 \mathrm{Mo} ; 4.8 \mathrm{Nb} ; 0.04 \mathrm{Mn}$; $0.002 \mathrm{~S} ; 0.006 \mathrm{P} ; \mathrm{Ni}$ - base.

As consumable electrodes the $55 \mathrm{~mm}$ diameter rods of KhN56MBYuDSh alloy, produced by vacuum-arc remelting, were used. After melting the ingot is subjected to heat treatment under the following conditions: homogenization $\left(1150{ }^{\circ} \mathrm{C}\right.$, $1 \mathrm{~h})$; hardening $\left(980{ }^{\circ} \mathrm{C}, 1 \mathrm{~h}\right)$; ageing $\left(730{ }^{\circ} \mathrm{C}\right.$, $15 \mathrm{~h})$ with repeated ageing $\left(650{ }^{\circ} \mathrm{C}, 10 \mathrm{~h}\right)$.

The longitudinal and transverse macrosections were cut out from the ingot to evaluate the structural homogeneity. Macrostructure, given in $\mathrm{Fi}-$
Table 1. Technological parameters of laser treatment with surface melting $\left(I=17 \mathrm{~A}, P_{\mathrm{em}} \approx 3 \mathrm{~kW}, 1.2-1.5 \mathrm{~mm}\right.$ beam diameter, $630 \mathrm{~mm} / \mathrm{min}$ speed of linear movement)

\begin{tabular}{|c|c|c||}
\hline Shielding atmosphere & $\begin{array}{c}\text { Width of } \\
\text { surface-melted layer, } \\
\mu \mathrm{m}\end{array}$ & $\begin{array}{c}\text { Depth of penetration, } \\
\mu \mathrm{m}\end{array}$ \\
\hline Nitrogen & 2050 & 270 \\
\hline Helium & 1850 & 240 \\
\hline
\end{tabular}

gure 1, is characterized by homogeneous dense structure. Defects of shrinkage origin, pores, cracks, slag inclusions were not observed.

The laser surface treatment of specimens was carried out using continuous $\mathrm{CO}_{2}$-laser in atmosphere of shielding gas of nitrogen and helium (Table 1).

Figure 2 shows specimens after laser surface melting in nitrogen and helium. Structure of the surface-melted zone is given in Figure 3.

Using the JEOL scanning electron microscope JSM-35CF (Japan) and «Oxford Instruments» $\mathrm{X}$-ray spectrometer with dispersion at energy of X-ray quanta INCA Energy-350 (Great Britain), and metallographic microscope «Neophot-32» equipped with attachment for digital photography, the structure of cast high-nickel alloy KhN56MBYuDSh before and after its laser treatment with surface melting in nitrogen and helium was evaluated. Taking into account the specifics of imaging the microstructure of cast alloy for electron microscope, the back-scattered electron imaging mode was used (Figure 3).

Investigations of cast metal in as-melted state showed that the structure contains phase inclusions (eutectics), i.e. light regions, having the increased amount of molybdenum, niobium and silicon (spectra 3, 4, Figure 4, Table 2), as compared to matrix metal (spectrum 5, Figure 4, Table 2). The dark inclusions of titanium carbonitride were also revealed in matrix structure, which contain the increased amount of carbon,
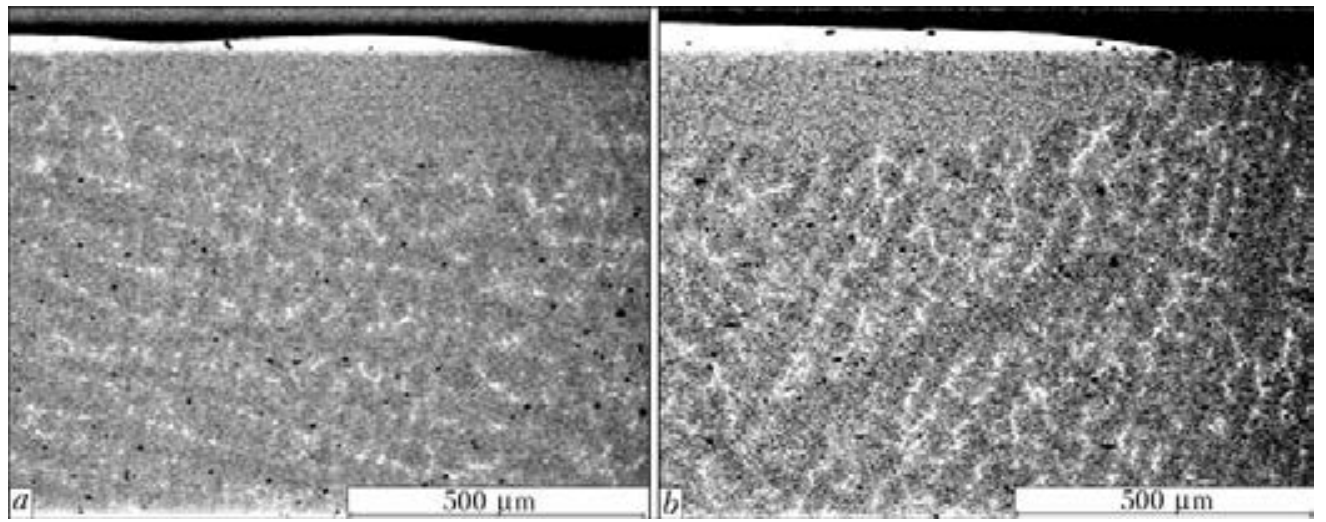

Figure 3. Microstructure of surface-melted zone in atmosphere of nitrogen $(a)$ and helium $(b)$, obtained by application of SEM BEI mode 


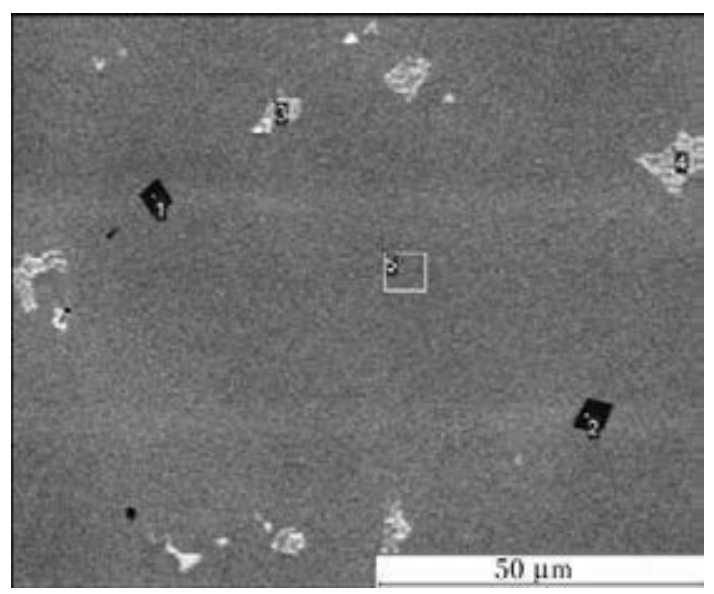

Figure 4. Microstructure of cast metal of alloy KhN56MBYuDSh without laser treatment

nitrogen, titanium and niobium (spectra 1, 2, Figure 4, Table 2).

Examination of metal after laser treatment in nitrogen showed that the surface melting results in dispersion of eutectics, i.e. light regions in matrix structure, containing increased amount of niobium and molybdenum. Refining of inclusions of carbonitrides (dark inclusions in matrix structure) is occurred (Figure 5, $a$; Table 3). The external surface of remelted metal has a golden tint, typical of the titanium nitride.

Investigation of metal after laser treatment with surface melting in helium showed that as a result of laser surface melting the dispersion of eutectics (light regions in matrix structure), containing the increased amount of niobium and molybdenum, refining of titanium carbonitrides (dark inclusions in matrix structure) is also occurred in HAZ. However, in the surface-melted zone the almost complete absence of inclusions of titanium carbonitrides is observed (Figure 5, $b$; Table 4).
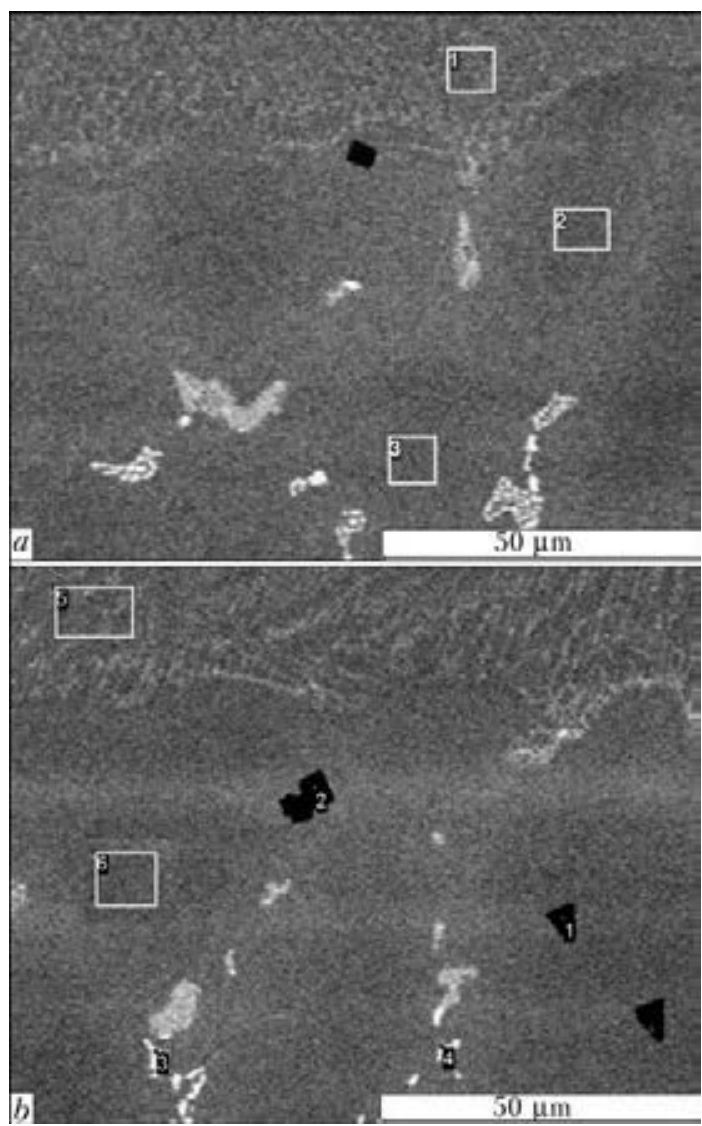

Figure 5. Microstructure of surface-melted zone (upper area) and cast metal (lower) of alloy KhN56MBYuDSh after laser treatment in nitrogen $(a)$ and helium $(b)$

Optical metallographic examinations of cast metal of high-nickel alloy KhN56MBYuDSh were carried out on etched sections (in reagent of $5 \mathrm{mg} \mathrm{CuCl}{ }_{2}+100 \mathrm{ml} \mathrm{HCl}+100 \mathrm{ml}$ ethanol), using microscope «Neophot-32» with attachment for digital photography.

The clearly expressed dendritic structure, typical of cast metal, was revealed in base metal

Table 2. Chemical composition (wt.\%) of local regions (see Figure 4)

\begin{tabular}{||c|c|c|c|c|c|c|c|c|c|c|c||}
\hline $\begin{array}{c}\text { Number of } \\
\text { spectrum }\end{array}$ & $\mathrm{C}$ & $\mathrm{N}$ & $\mathrm{Al}$ & $\mathrm{Si}$ & $\mathrm{Ti}$ & $\mathrm{V}$ & $\mathrm{Cr}$ & $\mathrm{Fe}$ & $\mathrm{Ni}$ & $\mathrm{Nb}$ & $\mathrm{Mo}$ \\
\hline 1 & 6.87 & 17.77 & 0 & 0 & 49.28 & 2.58 & 2.16 & 0.35 & 1.31 & 19.09 & 0.59 \\
\hline 2 & 6.99 & 17.97 & 1.03 & 0.27 & 50.74 & 0.34 & 1.66 & 1.77 & 3.44 & 14.68 & 0.91 \\
\hline 3 & 2.94 & 0 & 0.59 & 1.23 & 0.31 & 0.20 & 13.11 & 10.51 & 40.28 & 15.30 & 13.55 \\
\hline 4 & 4.14 & 0 & 0.75 & 0.92 & 0.47 & 0.25 & 13.28 & 10.15 & 42.24 & 17.31 & 10.48 \\
\hline 5 & 0 & 0 & 1.19 & 0.22 & 0.15 & 0.36 & 17.78 & 15.62 & 55.53 & 2.47 & 5.01 \\
\hline
\end{tabular}

Table 3. Chemical composition (wt.\%) of local regions (see Figure 5, $a$ )

\begin{tabular}{|c|c|c|c|c|c|c|c|c|c|c|c|}
\hline $\begin{array}{c}\text { Number of } \\
\text { spectrum }\end{array}$ & $\mathrm{C}$ & $\mathrm{N}$ & $\mathrm{O}$ & $\mathrm{Al}$ & $\mathrm{Ti}$ & $\mathrm{V}$ & $\mathrm{Cr}$ & $\mathrm{Fe}$ & $\mathrm{Ni}$ & $\mathrm{Nb}$ & $\mathrm{Mo}$ \\
\hline 1 & 3.68 & 0 & 0 & 1.18 & 0.36 & 0.30 & 16.82 & 14.02 & 54.02 & 3.94 & 5.67 \\
\hline 2 & 2.60 & 0 & 1.01 & 1.20 & 0.19 & 0.40 & 17.67 & 15.33 & 53.76 & 2.68 & 5.16 \\
\hline 3 & 2.82 & 0 & 0 & 1.26 & 0.25 & 0.43 & 17.58 & 13.98 & 54.45 & 3.56 & 5.67 \\
\hline
\end{tabular}


SCIENTIFIC AND TECHNICAL

Table 2. Chemical composition (wt.\%) of local regions (see Figure 5, b)

\begin{tabular}{||c|c|c|c|c|c|c|c|c|c|c|c|c||}
\hline \hline $\begin{array}{c}\text { Number of } \\
\text { spectrum }\end{array}$ & $\mathrm{C}$ & $\mathrm{N}$ & $\mathrm{O}$ & $\mathrm{Al}$ & $\mathrm{Si}$ & $\mathrm{Ti}$ & $\mathrm{V}$ & $\mathrm{Cr}$ & $\mathrm{Fe}$ & $\mathrm{Ni}$ & $\mathrm{Nb}$ & $\mathrm{Mo}$ \\
\hline 1 & 5.58 & 18.70 & 3.94 & 0 & 0 & 48.79 & 1.78 & 1.64 & 0.27 & 1.34 & 17.12 & 0.83 \\
\hline 2 & 6.56 & 15.23 & 5.04 & 0.11 & 0 & 49.19 & 1.65 & 1.23 & 0.43 & 1.33 & 18.53 & 0.70 \\
\hline 3 & 5.51 & 0 & 0 & 1.22 & 0.14 & 0.30 & 0.30 & 15.66 & 12.21 & 53.96 & 5.35 & 5.35 \\
\hline 4 & 5.91 & 0 & 1.72 & 0.54 & 1.26 & 0.23 & 0.20 & 13.42 & 9.79 & 38.28 & 14.81 & 13.83 \\
\hline 5 & 2.68 & 0 & 0 & 1.25 & 0.17 & 0.28 & 0.50 & 17.12 & 14.14 & 54.16 & 3.92 & 5.79 \\
\hline 6 & 0 & 0 & 0 & 1.23 & 0.14 & 0 & 0.45 & 18.14 & 15.84 & 57.33 & 2.07 & 4.80 \\
\hline
\end{tabular}

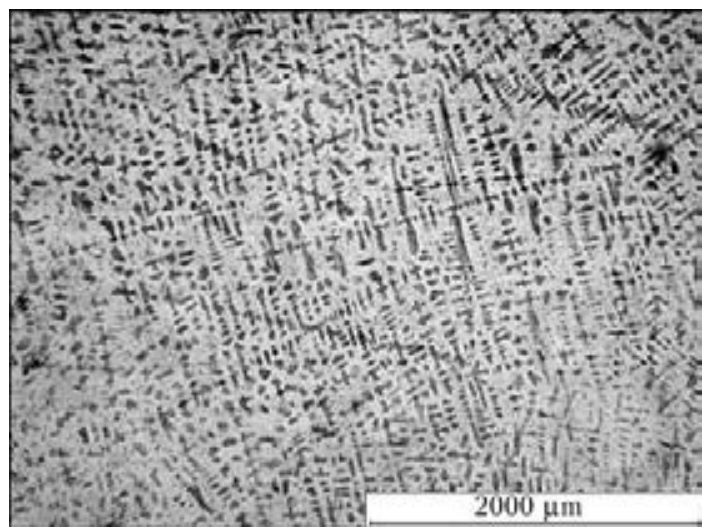

Figure 6. Microstructure of as-melted cast metal of alloy KhN56MBYuDSh

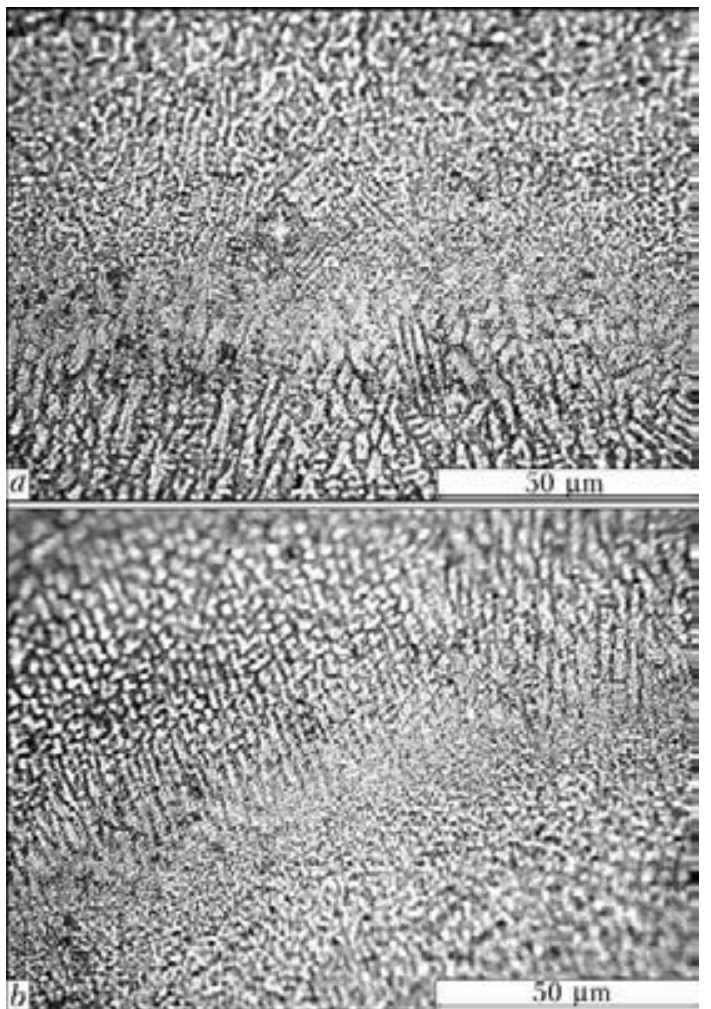

Figure 7. Microstructure of surface-melted zone of cast metal of alloy KhN56MBYuDSh after laser surface treatment in nitrogen $(a)$ and helium $(b)$ even after its laser surface treatment in nitrogen and helium (Figures 6 and 7 ).

For comparison and quantitative description of dendritic structure the parameter was selected in the form of distance between the primary branches of dendrites. The distance between the secondary branches of dendrites was selected as a characteristic of dispersity of the dendritic structures. This distance was evaluated by using the metallographic investigations with application of computer program Tescan.

It was found that in as-melted cast metal the distance between the primary branches of dendrites is varied from 224 up to $862 \mu \mathrm{m}$, and it is 60-245 $\mu \mathrm{m}$ between the secondary ones, i.e. the distance between the primary branches is almost 3 times longer than that between the secondary ones.

In the surface-melted zone in nitrogen atmosphere the distance between the primary branches of dendrites is $1.8-5.0 \mu \mathrm{m}$, between the secondary ones $-1.6-4.2 \mu \mathrm{m}$; in helium the distance between the primary branches is $1.9-4.5 \mu \mathrm{m}$ and between the secondary ones $-1.5-4.2 \mu \mathrm{m}$. The distances between the primary and secondary branches of dendrites in the surface-melted zone

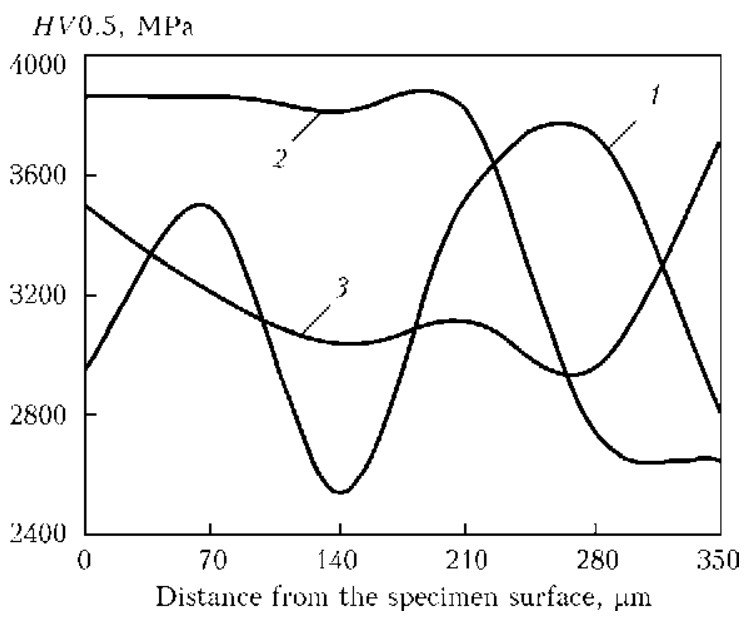

Figure 8. Distribution of microhardness in cast metal of alloy KhN56MBYuDSh: 1 - in as-melted state; 2, 3 - in surface-melted zone after laser treatment, respectively, in nitrogen and helium 
in atmosphere of nitrogen and helium are almost similar, moreover, they are by 2 orders shorter than in as-melted cast metal without laser treatment.

Durometric investigations were carried out in the LECO hardness meter M400 at $0.05 \mathrm{~kg}$ load. The results of analysis of distribution of microhardness in the surface-melted zone of surface layer, produced as a result of laser treatment in atmosphere of nitrogen and helium, as well as cast metal without laser treatment, are presented in Figure 8. In the surface-melted zone the more uniform distribution of microhardness is observed as compared with cast metal without laser treatment. In addition, it was found that the level of microhardness of the surface-melted zone after laser treatment in nitrogen is higher than that of surface layer of surface-melted zone in helium.

\section{Conclusions}

As result of laser surface treatment with surface melting of cast high-nickel alloy KhN56MBYuDSh a homogeneous layer of 240$270 \mu \mathrm{m}$ thickness is formed on its surface, in which the dispersion of eutectics, enriched with molybdenum and niobium, and refining of carbonitride inclusions of titanium are occurred.

Durometric investigations showed that the microhardness is averaged in the whole volume of surface-melted layer, as compared with cast metal without the laser treatment, moreover, the microhardness of cast metal matrix is at the level of 2600-2900 MPa, of surface-melted layer in helium - 3100-35000 $\mathrm{MPa}$, and of surfacemelted layer in nitrogen $-3800-3900 \mathrm{MPa}$. The increase in level of microhardness of surfacemelted layer in use of nitrogen as a shielding gas can be predetermined by some level of metal nitriding, that is proved by a golden tint of the external surface, characterizing the presence of titanium nitrides on the surface.

It was found as a result of metallographic investigations that in cast metal without laser treatment the distance between the primary branches of dendrites is approximately 3 times longer than that between the secondary ones, while in the surface-melted zone the distance between the primary and secondary branches of dendrites is almost similar. In addition, in the surface-melted zone the distance between the branches of dendrites by 2 orders shorter than in as-melted cast metal without laser treatment.

In general, the laser treatment with surface melting favorably influences the structure and properties of cast high-nickel alloy KhN56MBYuDSh, providing the formation of quality homogeneous surface working layer.

1. Sadovsky, V.D., Schastlivtsev, V.D., Tabatnikova, T.M. et al. (1989) Laser heating and structure of steel: Atlas of microstructures. Sverdlovsk: UrO AN SSSR.

2. Brover, A.V., Diachenko, L.D. (2009) Peculiarities of structure formation in zones of laser surface melting of metals and alloys. Metallovedenie $i$ Termich. Obrab. Metallov, 1, 29-33.

3. Chudina, O.V., Aleksandrov, V.A., Brezhnev, A.A. (2010) Combined surface strengthening of carbon steels by laser alloying with subsequent nitriding. Uprochn. Tekhnologii i Pokrytiya, 4, 33-37.

4. Tikhonov, V.A., Medovar, B.I., Saenko, V.Ya. et al. (1990) Producing of hollow ingot of high-nickel alloy by ESC method. Problemy Spets. Elektrometallurgii, 2, 39-42.

5. Bashnin, Yu.A., Korostylyov, A.B. (1993) Selection of conditions for quenching of electroslag remelted alloy KhN56MBYuD. Metallovedenie $i$ Termich. Obrab. Metallov, 3, 19-23.

6. Paton, B.E., Chepurnoj, A.D., Saenko, V.Ya. et al. (2004) Prospects of application of electroslag technologies in production of high-pressure vessels. $A d-$ vances in Electrometallurgy, 1, 2-8.

Received 24.12.2013 